Filo. y Lingür.8(1 y2):45-64,1982.

\title{
LOS NIVELES NARRATIVOS Y LA PERSONA DEL NARRADOR EN UN CORPUS DE JORGE LUIS BORGES
}

\section{Oscar Montanaro Meza}

\section{INTRODUCCION}

Dos aspectos configuran el tema aquí propuesto, a saber, el aspecto literario: un corpus narrativo seleccionado de la narrativa borgiana por un lado, y por otro, los dos elementos metodológicos siguientes: los niveles narrativos y la persona del narrador, conceptos que forman parte de la narratología expuesta por Gérard Genette en su ensayo "Discours du récit, essai de méthode" (1). En cuanto a la hipótesis formulada, resulta ésta de la proyección de los aspectos teóricos indicados, sobre las perspectivas narrativas establecidas en el corpus seleccionado y se enuncia de la manera siguiente:

"El mundo narrado se dispone, en estos relatos, en las formas de una narración metadiegética y en una relación homodiegética".

\section{A. Delimitación conceptual de los niveles narra- tivos.}

Dentro de un relato se puede narrar otro relato, y aún dentro de éste otro más; en tales casos, la narración constará de varios niveles narrativos; cuando ello se da es explicado por Gérard Genette así:

"...tout événement reconté par un récit est à un niveau diégétique immédiatement supérieur à celui où se situe l'acte narratif producteur de ce récit". (p. 238)

Luego, Genette precisa que el relato primero posee una instancia narrativa extradiegética y que, en el relato metadiegético (segundo relato) la instancia es intradiegética.

Algunas posibilidades de la instancia narrativa en la narración extradiegética, según Genette. son las que siguen:

a) El narrador "autor" (quien se dirige a un público calificado, o bien a nadie en particular).

b) El diario íntimo.

c) Las epístolas a un destinatario interno, o la relación epistolar entre varios.

ch) La corriente de la conciencia misteriosamen- te captada y transcrita por el narrador, directamente del personaje. (Cfr. p. 240).

En cuanto a las posibilidades de la narración intradiegética Genette establece, a modo de ilustración, las siguientes:

a) El relato oral.

b) El texto escrito.

c) La obra dentro de la obra.

ch) El relato interior, ya sea un sueño, o bien cualquier hecho rememorado.

d) La representación no verbal.

Entre el relato metadiegético y el relato extradiegético dentro del cual aquél se incluye, existen tres tipos de relación:

a) Relación de causalidad directa entre la metadiégesis y la diégesis, el relato segundo explica el primero.

b) La relación temática, en cuyo caso, subraya Genette, la relación indirecta es "purement thématique", porque no existe la continuidad ni espacial, ni temporal entre el relato primero y el metarrelato.

c) La relación explícita entre los dos niveles de la historia está ausente y, lo que importa, realmente, es

“...l' acte de narration lui même que remplit une fonction dans la diégèse, indépendamment du contenu métadiégétique: fonction de distraction, par exemple, et/ou d' obstruction" (p. 243).

Cuando en el relato se presentan cambios de nivel narrativo, que no son producidos por otras instancias narrativas, emplea Genette el concepto de metalepsis, cuyo significado expresa una serie de posibilidades en las cuales el narrador y el narratario extradiegético o ambos, se introducen en el mundo diegético. Anota además, que esta incursión produce

...un effet de bizarrerie soit bouffonne... soit fantastique" (p. 244).

Esa frontera ondulante entre planos diferentes, esa incursión de lo contado con la realidad, o 
viceversa, es precisamente, la preocupación manifiesta de Jorge Luis Borges, la cual es recogida por Genette en esta cita del autor argentino:

"De telles inventions suggèrent que si les personnages d'une fiction peuvent être lecteurs ou spectateurs, nous, leurs lecteurs ou spectateurs, pouvons être des personnages fictifs"' (p. 245) (2).

\section{B. Delimitación conceptual de la persona del na- rrador.}

Gérard Genette parte en su análisis sobre la persona del narrador, del hecho frecuente de que el autor no selecciona la primera, la segunda o la tercera persona para su narración, sino que ellas reflejan la actitud narrativa que él asume, o sea:

“...faire raconter l'histoire par l'un de ses 'personnages', ou par un narrateur étranger à cette histoire". (p.252)

Así pues, la presencia de formas verbales en primera persona, en un texto narrativo conduce a dos situaciones muy distintas, que en un estudio gramatical no son pertinentes, pero que sí lo son en un análisis del discurso narrativo:

"...la désignation du narrateur en tant que tel par lui même... et l' identité de personne entre le narrateur et I'un des personnages de I' histoire..." (p. 252)

Según la circunstancia de que el personaje sea "extraño" a la narración o incorporado a la misma, distinguirá Genette dos tipos de narrador:

a) Heterodiegético: si se encuentra ausente la historia que cuenta.

b) Homodiegético: si está presente como personaje en la historia que cuenta.

En este último caso, se distinguirá al narrador-héroe de su relato, del narrador que es un observador, un testigo de los acontecimientos que cuenta. Al primer caso, Genette lo designa "autodiegético".

Apunta el narratólogo francés que en la relación entre el narrador y su historia, se presentan dos transgresiones: la primera, en la cual narradores presentes en la narración desaparecen discretamente para luego, aparecer de nuevo, y la segunda, por medio de un cambio de la persona gramatical para designar al mismo personaje, como lo ilustra con el ejemplo siguiente en que alude a un cuento de Borges:
"C'est sans doute Borges qui nous offre l'example plus spectaculaire de cette transgression, ... dans le conte intitulé La Forme de l'épée [sic], où le héros commencé par raconter son aventure infâme en s' identifiant à sa victime, avant d'avouer, qu'il est en fait l'autre, le lâche dénonciateur jusque-la traité, avec le mépris qu'il faut, en troisième personne" "' (p. 254).

La transgresión apuntada, en la cual las identidades de los personajes se confunden (víctima-traidor), complementa una idea que se destaca en otros relatos borgianos: lo hecho por un hombre es como si lo hicieran todos los hombres. Esta confusión de personajes la proyecta el narrador fuera del ámbito literario, cuando manifiesta como el autor y el lector se confunden en el acto de la lectura (3).

Con la clasificación del narrador según su relación con la historia y con la clasificación del nivel narrativo, establece Genette (Cfr. p.p. 255-256) los cuatro tipos de estatus del narrador:

a) Extradiegético-heterodiegético: la instancia narativa se sitúa en un primer plano narrativo y cuenta una historia de la cual está ausente.

b) Extradigético-homodiegético: ocurre cuando la instancia cuenta una historia en la que participa como personaje héroe, o como personaje observador o testigo.

c) Intradiegético-heterodiegético: sucede en este caso, que la instancia narrativa se sitúa en un segundo nivel narrativo y se halla ausente de la historia que narra.

ch) Intradiegético-homodiegético: se da si la instancia narrativa se sitúa en un segundo nivel narrativo y cuenta una historia en la cual participa como personaje héroe, o como personaje observador o como testigo.

\section{El corpus.}

'El corpus seleccionado para este estudio, lo constituyen diez relatos que pretenden ser representativos de la creación narrativa de Jorge Luis Borges. Tres criterios privaron en la escogencia de los mismos, a saber:

1. El cronológico: cuentos escritos entre 1935 y 1975.

2. El de estudio sobre la narrativa borgiana: cuentos que han sido exhaustivamente co- 
mentados por la crítica.

3. El juicio de su autor: cuentos que Borges considera como los más relevantes de su creación narrativa, en particular: "El Sur" y "La intrusa".

A continuación se ofrece la lista de los cuentos escogidos con el nombre de la revista, o del diario, o del libro en que el cuento fue publicado por primera vez, así como el año de publicación: (4)

"Hombre de la esquina rosada" Historia Universal de la Infamia. 1era. edición. 1935.

"Tlön, Uqbar, Orbis Tertius" Sur. No. 68. 1940

"Las ruinas circulares" Sur. No. 75. 1940.

"Funes el memorioso" La Nación. Buenos Aires, 7 de junio. 1942.

“El Aleph" Sur. No. 131. 1945.

“Emma Zunz" Sur. No. 167. 1948.

"El Sur" La Nación. Buenos Aires, 8 de febrero. 1953.

"La intrusa" El Aleph. 6a. ed.(5). 1966.

"El informe de Brodie" El informe de Brodie. 1era. edición. 1970.

"El otro" El libro de arena. . 1era. Edic. 1975.

\section{ANALISIS DEL CORPUS}

La posición del narrador respecto a la enuriciación de la diégesis y la persona que éste asume en tal enunciación se desarrollarán conjuntamente, con el fin de lograr más unidad en la exposición. En cada cuento se indicará su nivel narrativo; luego se caracterizará la persona del narrador y se ofrecerán aquellos datos sobresalientes que favorezcan su relación con la diégesis, en la cual él participa, en mayor o menor grado, o bien si se encuentra ausente de la historia. Asimismo se aprovecharán las referencias que definan al narratario de estos cuentos, tanto en su nivel como en su relación con la historia.

Como fue señalado en la explicación sobre los niveles narrativos, tal aspecto teórico de la na- rratología de Gérard Genette adquiere relevancia al aplicarlo en el análisis de los relatos borgianos, ya que permite visualizar en el plano de la obra literaria, lo que sucede en el plano real en la génesis de la obra literaria:

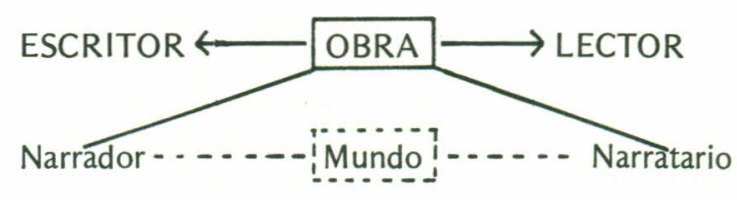

En algunos de sus ensayos Borges alude a la concepción del mundo según la cual el universo es un libro, los hombres son las palabras y Dios su autor, Concretamente en el ensayo "Del culto de los libros" (6) expone las ideas en torno de esta concepción del universo, fundamentado en citas de autores de diferentes épocas y de distintas corrientes filosóficas y religiosas. Así por ejemplo, la siguiente cita que Borges transcribe indirectamente de Carlyle:

"[Carlyle]... estampó que la historia universal es una Escritura Sagrada que desciframos y escribimos inciertamente, y en la que también nos escriben" (7).

De acuerdo con lo dicho, sobre el esquema anterior se tendrá este plano superior:

\section{AUTOR ESCRITURA SAGRADA HOMBRE}

El hombre es pues, a la vez, "sujeto" de la escritura y "lector" de la misma.

Completado el cuadro teórico-metodológico, se expondrán a continuación el análisis de los diez cuentos y se seguirá para ello un orden cronológico, según el año en que cada uno de los cuentos fue publicado por primera vez.

\section{A. "Hombre de la esquina rosada".}

En este relato surge una estructura metadiegética, ya que el compadrito cuenta al narrador primer la historia vivida por él durante "esa noche" (8).

El narrador autodiegético inicia y concluye su historia, sin que el narrador primero lo interrumpa, o haga siquiera, alguna observación. Sólo 
al final del cuento el compadrito evoca al narrador primero.

La caracterización del narrador autodiegético se da conforme avanza su narración; por lo que se desprende del párrafo anterior el narrador extradiegético no suministra ningún dato sobre el nivel de la historia, ni tampoco sobre su relación con la misma; simplemente, transcribe la enunciación hecha por el segundo narrador autodiegético, o sea el compadrito.

Con las primeras palabras del cuento el compadrito hace sentir su actitud jactanciosa ante la presencia de quien, o quienes, lo escuchan:

"A mí, tan luego, hablarme del finado Francisco Real". (O.C. p. 329).

Mas la alusión directa a su "auditorio" aparece cuando el narrador alude a Rosendo Juárez, el Pegador:

\footnotetext{
"A ustedes, claro que les falta la debida experiencia para reconocer ese nombre..." (Idem).
}

Así pues, el compadrito se dirige a personas que no pertenecen a su mundo social y ante quienes su acción pueda ser rechazada, de aquí lo cauteloso para revelar que él fue quien asesinó a Francisco Real, el Corralero; de esta forma su historia es escuchada (leída) hasta el final, sin que el narratario, ajeno al mundo violento del compadrito, se escandalice, asimilando la violencia de la historia.

El compadrito relata cómo él es visto por Rosendo Juárez:

"-Vos siempre has de servir de estorbo, pendejo- me rezongó al pasar..." (O.C. p. 332)

Inmediatamente ante el insulto de Rosendo, el compadrito reflexiona y se siente un ser insignificante:

"...yo era apenas otro yuyo de esas orillas, criado entre las flores de sapo y las osamentas". (Idem)

Menospreciado por Rosendo y por él mismo, el compadrito no soportó la humillación que lanzó el corralero a los hombres del barrio y por ello lo asesina. Con su acción venga a los suyos y, en consecuencia, él se siente más hombre, como lo manifiesta cuando se refiere a quienes le roban al muerto:
“... que así se le animaban a un pobre, difunto indefenso, después que lo arregló otro más hombre”. (O.C. p. 334).

Además de esa hombría, el narrador refleja tranquilidad y sosiego espiritual, al fin y al cabo, la deshonra lavada con la sangre del injuriador purifica la acción del asesinar, como lo destaca la metonimia que cierra la narración:

"...y estaba [el cuchillo] como nuevo, inocente, y no quedaba ni un restrito de sangre". (Idem).

El narratario a quien se dirige el compadrito se configura de una presencia múltiple a una concreta y propia. Véanse las citas:

1) "A ustedes, claro que les falta..." (O.C. p. 329).

2) "Era un local que usté lo divisaba de lejos". (Idem)

3) "Se murió, señor, y digo que hay años en que ni pienso en ella [La Lujanera]". (O. C. p. 330).

4) “Recordarán ustedes aquella ventana alargada..." (O.C. p. 334).

5) “Aprovechadores, señor, que así..." (Idem).

6) "Entonces, Borges, volvi a sacar el cuchillo corto y filoso..." (Idem).

Nótese como en la última cita aparece el narrador primero y es la única referencia que existe en toda la narración. Este párrafo constituye el desenlace del cuento, por la declaración indirecta que hace el narrador autodiegético ante Borges de que él es quien vengó el honor del barrio.

En resumen, el narrador primero, "Borges", no informa sobre la enunciación del relato del compadrito, sino que la ofrece directamente, sin mediar su voz narrativa, respetando la voz del protagonista y sin caer en la tentación literaria de añadir o de acentuar algún detalle.

\section{B. "Tlön, Uqbar, Orbis Tertius".}

La narración se inicia con esta forma verbal: "Debo...", en la cual tácitamente se encuentra el sujeto que narra. Este "yo" había discutido con su amigo "Bioy Casares" sobre

“...la ejecución de una novela en primera persona, cuyo narrador omitiera o desfigurara los hechos e incurriera en diversas contradicciones, que permitieran a unos pocos lectores... la adivinación de una realidad atroz o banal". (O.C. p. 431). 
Larga es la cita, pero importante ya que en ella se reflejan los rasgos del narrador y del narratario, así como la estructura de este cuento.

Sea dicho en otras palabras, la cita en el espejo que recoge la imagen del mundo narrado de "Tlön, Uqbar, Orbis Tertius.

El tema de la discusión, la presencia de un espejo y la existencia de una enciclopedia son los elementos introductorios de la historia. El narrador, impulsado por una cita que "Bioy Casares"le hace, después de la conversación referida y ante la inquietante presencia de un espejo, sobre una frase dicha por herisarca de Uqbar, investiga sobre esa misteriosa región geográfica. La existencia de esta región no la registran ni los atlas, ni la enciclopedia que el narrador posee en la quinta, sólo en las últimas cuatro páginas adicionales del XLVI tomo de la Anglo-American Cyclopaedia perteneciente a "Bioy Casares", y a pesar de que es de la misma edición de la que se encuentra en la quinta, posee la siguiente diferencia:

“...en vez de 917 páginas constaba de 921. Esas cuatro páginas adicionales comprendían el artículo sobre Uqbar". (O.C. p. 432)

Cuenta el narrador de la lectura que efectuaron "Bioy" y él de las cuatro páginas adicionales de la enciclopedia y de esa lectura ofrece una síntesis de la geografía, del idioma y de la literatura de Uqbar. Indica, además, la bibliografía que acompañaba al artículo y que

"...enumeraba cuatro volúmenes que no hemos encontrado hasta ahora..." (Idem).

La información que da el narrador resumiendo el contenido de la Enciclopedia sobre Uqbar y la vana búsqueda de otras fuentes bibliográficas que registren el nombre de este país, son los hechos que integran la primera parte del relato.

En la segunda parte, el narrador cuenta los detalles de cómo

"Ahora tenía en las manos un vasto fragmento metódico de la historia total de un planeta desconocido..." (O.C. p. 434).

La descripción aludida aparece en una apócrifa obra escrita en inglés y titulada: $A$ first Encyclopaedia of Tlön. Vol. I, Hlaer to Jangr. En este tomo hay referencias sobre otros tomos y la descripción del contenido sobre Tlön es semejante, aunque con más pormenores, a la hecha sobre Uqbar.
En la tercera parte del relato el narrador indica cómo Tlön, mundo fantástico, se va introduciendo en el mundo real y cómo ese mundo fantástico se enseñorea de la realidad, gracias al trabajo persistente de

"Una dispersa dinastía de solitarios..." (O.C. p. 443).

Según el somero resumen de la diégesis, esta se sustenta en informaciones bibliográficas y desde este punto se genera una narración metadiegética, cuyos hechos llegan a incursionar en la "realidad" de la narración primera. Los informes que se facilitan, en términos generales, no los ofrece directamente el narrador; y es así que la transcripción directa más importante es la que da el núcleo motivador del relato:

"El texto de la Enciclopedia decía: para uno de esos gnósticos, el visible universo era una ilusión o (más precisamente) un sofisma. Los espejos y la paternidad son abominables (mirrors and fatherhood are hateful) porque 10 multiplican y lo divulgan". (O. C. p. 432).

Consecuentemente, el narrador extradiegético asume la narración intradiegética, cuyos autores, los diversos sabios que crearon a Tlön, se diluyen en la grandiosidad de la obra y son opacados por el narrador primero, quien resume lo que lee $y$ lo transcribe. Este narrador extradiegético sostiene en la primera y en la segunda parte una relación heterodiegética con la historia de Tlön y de Uqbar; en cambio, en la tercera: las intromisiones de los objetos de Tlön lo convierten en un narrador homodiegético. Son estas intromisiones, estas metalepsis, que clasifican a "Tlön, Uqbar, Orbis Tertius" como un relato fantástico. La naturaleza fantástica del relato se comprueba también con la consideración de que el relato está bajo el predominio de la primera persona, lo cual conviene a la literatura fantástica según lo destaca Tzvetan Todorov:

"El narrador representado conviene a lo fantástico, pues facilita la necesaria identificación del lector con los personajes" (9).

El narrador extradiegético posee conciencia de su papel de escritor, como lo reflejan sus sentimientos expresados cuando encuentra el undécimo tomo de la enciclopedia: 
"Me puse a hojearlo y sentí un vértigo asombrado y ligero que no describiré porque esta no es la historia de mis emociones sino de Uqbar y Tlön y Orbis Tertius". (O. C. p. 434).

También se presenta como amigo de varios intelectuales ilustres y como un intelectual tan acucioso como ellos, según se desprende de la cita indirecta y ficticia de Alfonso Reyes, quien

"...harto de esas fatigas subalternas de indole policial, propone que entre todos acometamos la obra de reconstruir los muchos y macizos tomos que faltan..." (Idem).

Este narrador, como se ha visto, se apoya en testimonios literarios (enciclopedias y otras referencias similares) con el fin de asentar la verosimilitud del mundo narrado y acude a recursos propios del ensayo (10) como lo son las frecuentes referencias a conocidos y destacados escritores latinoamericanos (Bioy Casares, Alfonso Reyes, Ezequiel Martínez Estrada, Amorin, Xul Solar, Carlos Mastronardi) y europeos (La Rochelle y Russell); las citas de libros ficticios y reales; el señalamiento de lugares geográficos, que de una u otra manera, directa o indirectamente se mezclan en la creación del imaginario mundo; en fin, las notas al pie de página. Todas estas referencias poseen la cualidad de acentuar la verosimilitud de la narración.

Otro rasgo que define al narrador son sus dudas que nacen en varias ocasiones y que además son una forma de mantener el contacto con el narratario. Obsérvense estos ejemplos:

"Los dos (según creo haber indicado) son reimpresiones..." (O.C. p. 432).

"Entiendo que era viudo, sin hijos". (O. C. p. 433) *

"...yo pienso que sus tigres transparentes y sus torres de sangre no merecen, tal vez, la continua..." (O. C. p. 435).

"Si nuestras previsiones no erran, de aquí a cien años alguien descubrirá los cien tomos de la Segunda Enciclopedia de Tlön". (O. C. p. 443).

Además de esas alusiones el narrador se dirige más explícitamente al narratario en varios pasajes, como los siguientes:

\footnotetext{
"Han ocurrido tantas cosas desde esa fecha... Me limitaré a recordarlas". (O. C. p. 440).

"Lo demás está en la memoria (cuando no en la esperanza o en el temor) de todos mis lectores". (O. C. p. 442).

El narratario es configurado por el narrador primeramente, como un lector de ensayos, porque
}

la lectura ha de ser reflexiva y luego, como lector de un relato fantástico, cuando el narrador lo incorpora a su mundo pasándolo al nivel de narratario intradiegético.

\section{C. "Las ruinas circulares".}

Su nivel narrativo es extradiegético. Sin embargo ha de tenerse en cuenta que en el relato "Examen de la obra de Herbert Quain" el narrador que examina la obra de Quain afirma:

"Del tercero The Rose of Yesterday, yo cometí la ingenuidad de extraer Las ruinas circulares, que es una de las narraciones del libro. El jardín de senderos que se bifurcan". (O. C. p. 464).

No se considera el relato como metadiegético ya que la referencia no pertenece al texto y se transcribió la cita anterior es para comprobar como Jorge Luis Borges acude a la técnica de la obra dentro de la obra. En consecuencia, se reitera el nivel extradiegético del narrador, quien al reunir los hechos elaborados "por ciertos narradores" desliza su relato (Cfr. O. C. p. 454) hacia elementos de una estructura metadiegética, sin que la misma llegue a configurarse tampoco como tal.

El epígrafe que presenta el narrador demanda un narratario a quien se le supone conocedor del inglés, ya que la idea de la cita expresada, repercute en el contenido del cuento.

La persona del narrador no se involucra en la acción del mago y transmite los pensamientos y las sensaciones de éste con el estilo indirecto. Su papel de narrador está en un primer plano y su identificación con los sentimientos del protagonista se presenta con fuerza vinculante; esto motiva que el desenlace de la historia adquiera mayor dramatismo.

El narrador tan seguro de las ideas y de los sentimientos del mago, muestra incertidumbre, ante hechos externos al mundo interior del mago. Por ejemplo:

\footnotetext{
"...repechó la ribera sin apartar (probablemente sin sentir) las cortaderas que le dilaceraban las carnes..." (O. C. p. 451).

“...se arrojó a los pies de la efigie que tal vez era un tigre y tal vez un potro, e imploró..." (O. C. p. 453).
}

Esas dudas desperdigadas en todo el relato refuerzan la complejidad de este narrador extradiegético. 
El narrador va presentando al narratario datos que intensificarán el desenlace de la diégesis al enunciar rasgos del hijo que son propios de la naturaleza del mago, como se aprecia en este cuadro:

\section{MAGO}

"...su patria era una de las infinitas aldeas que están aguas arriba". (O. C. p. 451).

Llega a "un templo... cuyo dios no recibe honor de los hombres". (Idem).

Temía que su hijo "descubriera de algún modo su condición de mero simulacro". (O. C. p. 454).

"Caminó contra los jirones de fuego. Estos no mordieron su carne... comprendió que él también era una apariencia..." (O. C. p. 455).

\section{HIJO}

"Le ordenó que... lo enviaría al otro templo... aguas abajo". (O. C. p. 453).

"Para que alguna voz lo glorificara en aquel edificio desierto". (O. C. p. 454).

"Antes (para que no supiera nunca que era un fantasma...) le infundió el olvido total..." (Idem)

"... le hablaron de un hombre mágico... capaz de hallar el fuego y de no quemarse". (Idem)

Este cuadro establece un paralelismo entre ambos personajes que llega a su naturaleza de simulacros; cada uno de ellos es un hombre creado por los sueños de otro hombre. Esta razón explica que en el sentido biológico ambos no mueren. Aseverar que el mago alcanza su "extinción" (11) es un decir que no se desprende del texto; el mago es un simulacro de hombre, que desaparecerá cuando el dios fuego deje de soñarlo y entonces, al hacerlo, se esfumará la presencia del mago y con éste, la de su hijo y así sucesivamente. De lo dicho se desprende que este relato sea mítico y no fantástico (12) como se le cataloga con frecuencia.

Para terminar el análisis del narrador de "Las ruinas circulares" se sostiene que la relación existente entre él y la diégesis es de índole heterodiegética, presentando en el párrafo inicial del cuento una característica homodiegética:
"Nadie lo vio desembarcar... nadie vio la canoa de bambú... pero a los pocos días nadie ignoraba... Lo cierto es que el hombre gris..." (O. C. p. 451).

El pronombre indefinido "nadie" incluye, implícitamente, al narrador, como lo evidencia cuando categórico se refiere a lo que él sí está seguro: "Lo cierto es..." A partir de esta contundente afirmación el narrador ofrece los sueños, los sentimientos y las acciones del mago cuya misión

"...no era imposible, aunque sí sobrenatural". (O. C. p. 451).

\section{$\mathrm{CH}$. "Funes el memorioso".}

El narrador extra-homodiegético de este relato ofrece una narración sobre hechos que acontecieron unos cincuenta años atrás y que giran en torno de un compadrito denominado Irineo Funes, o para delimitarlo mejor aún, de dos condiciones peculiares suyas. La primera, su aptitud de medir el paso del tiempo, como se indica en este pasaje:

"Bernardo le gritó imprevisiblemente: ¿Qué horas son, Irineo? Sin consultar el cielo, sin detenerse, el otro respondió: Faltan cuatro minutos para las ocho..." (O. C. p. 466).

La segunda, sobre su prodigiosa e infinita memoria, cualidad de la que el narrador presenta un detenido y reflexivo testimonio.

Como escritor e intelectual se presenta el narrador, participando junto con otros intelectuales en el proyecto de que quienes conocieron a Ireneo Funes escriban sobre él. Pero este narrador no sólo es otro intelectual más que escribirá sobre Ireneo, o con más precisión sobre su memoria, sino que además, posee conciencia de su esfuerzo creador al narrar la parte medular de su informe, o sea el diálogo que sostuvo durante aquella lejana noche con Funes el memorioso:

\footnotetext{
"Arribo, ahora, al más difícil punto de mi relato. Este (bueno es que ya lo sepa el lector) no tiene otro argumento..." (O.C. p. 487).
}

$Y$ ante las ingentes dificultades de su empresa, toma el sendero de la sencillez y de la verdad:

"No trataré de reproducir sus palabras, irrecuperables ahora. Prefiero resumir con veracidad las muchas cosas que me dijo Irineo". (O. C. p. 488).

Con el estilo indirecto no se precisa la "veracidad" de "las muchas cosas que le dijo Funes", 
pero sí en cambio, el narrador adquiere más trascendencia en la narración por las dos siguientes razones: a) el narrador homodiegético es quien atestigua sobre las facultades especiales del compadrito y b) su enunciación es hecha medio siglo después de haber acontecido los hechos. Ambas condiciones calzan para clasificar el texto dentro de lo fantástico, porque en definitiva, el discurso de quien narra posee un carácter ambiguo (13).

El narrador describe otros rasgos suyos:

1) Su carácter distraído:

"Yo soy tan distraído que el diálogo que acabo de referir no me hubiera llamado la atención...". (O. C. p. 486).

2) Su espíritu latinista y modesto:

"Mi valija incluía el De viris illustribus de Lhomond, el Thesaurus de Quicherat, los comentarios de Julio César y un volumen impar de la Naturalis historia de Plinio, que excedía (y sigue excediendo) mis módicas virtudes de latinista" (Idem).

Precisamente, estos libros motivarán el diálogo mencionado.

3) Su tendencia por dramatizar los hechos, como ocurre cuando recibió el telegrama en que se le solicitaba regresar a Buenos Aires de inmediato porque su padre estaba enfermo, lo lleva a fingir:

“...la tentación de dramatizar mi dolor, fingiendo un viril estoicismo, tal vez me distrajeron de toda posibilidad de dolor" (O. C. p. 487).

4) Su conmiseración hacia Funes, le permite acentuar la prodigiosa memoria de Ireneo Funes:

"Pensé que cada una de mis palabras (que cada uno de mis gestos) perduraría... me entorpeció el temor de multiplicar ademanes inútiles" (O. C. p. 490).

5) El narrador luce una magnífica memoria que es destacada al principio del cuento por el e:inpleo anafórico de la forma verbal "recuerdo" para referirse a pequeños detalles ocurridos cincuenta años atrás, en el transcurso de una noche.

6) Su discurso fático (14) le permite la presencia del narratario e involucrarlo en la historia. A continuación se dan estas referencias: la primera alusión se dirige a quienes preparan una obra sobre Funes. “...mi testimonio será acaso el más breve y sin duda el más pobre, pero no el menos imparcial del volumen que editarán ustedes" (O. C. p. 485). lectores:

La segunda, en que alude directamente a sus "...que mis lectores se imaginen los entrecortados períodos que me abrumaron esa noche" (O.C. p. 488).

También acude el narrador a alusiones indirectas; para ello usa el pronombre de primera persona en plural, lo que equivale a la presencia del narratario y del narrador en la misma forma verbal o en el mismo pronombre:

"Nosotros, de un vistazo, percibimos..." (O. C. p. 488).

"Los dos proyectos que he indicado... Nos dejan vislumbrar o inferir el vertigioso mundo de Funes" (O. C. p. 489).

"...el menos importante de sus recuerdos era más minucioso y más vivo que nuestra percepción de un goce físico..." (O. C. p. 490).

Esta característica, como ya se dijo, involucra al lector dentro del relato por medio de la primera persona del plural y se enfatiza más si se considera que también la emplea para referirse a la acción hecha por el "yo" que narra y por un personaje, según se aprecia en la cita siguiente:

"Yo volvía con mi primo Bernardo Haedo de la estancia de San Francisco. Volvíamos cantando, a caballo... Corrimos una especie de carrera con la tormenta. Entramos en un callejón..." (O. C. p. 485).

En síntesis, de esta relación entre el narrador homodiegético y su narratario se concluye que éste es configurado como cocreador de su obra e involucrado en su acontecer, lo cual es una característica del relato fantástico (15).

\section{D. "El Aleph"}

Aquí el narrador se coloca en un nivel extradiegético y establece una relación autodiegética, es decir, constituye el personaje principal de la historia.

Los epígrafes muestran que él se dirige a un público culto, ya que debe conocer el idioma inglés para comprender la cita de Hamlet y la del Leviathan transcritas en su lengua original.

El narrador es escritor, y aspira al reconocimiento público: 
"...increíblemente, mi obra Los naipes del tahur [16] no logró un solo voto" (O. C. p. 627).

Y como escritor se enfrenta a las dificultades de la creación cuando antes de describir el Aleph apunta:

"Arribo, ahora al inefable centro de mi relato; empieza, aquí, mi desesperación de escritor" (O. C. p. 624).

Más adelante pondera la objetividad de su escrito aludiendo que ante visiones semejantes a la suya, sus videntes, sus autores místicos: un persa (17), Alanus de Insulis y Ezequiel buscaron una imagen para significar la divinidad, pero que él no lo pretende ya que entonces:

"...este informe quedaría contaminado de literatura, de falsedad" (O. C. p. 625).

Si a lo dicho se añade el empleo de la posdata, las notas al pie de página y los nombres propios tomados de la realidad, se deduce que este relato posee un carácter de "informe", aunque cargado de humorismo e ironía.

El narratario de este cuento es aludido por el narrador en varias oportunidades: en las aclaraciones de la acción, en los énfasis del narrador puestos entre paréntesis, en las notas al pie de página, -las cuales complementan algún pasaje de la diégesis-y en los epígrafes.

En otros pasajes las alusiones son directas, como sucede en los siguientes ejemplos:

1) Se dirige a su narratario cuando el narrador, "Borges", se interroga, poco antes de describir el Aleph:

"¿Cómo trasmitir a los otros el infinito Alpeh, que mi temerosa memoria apenas abarca?" (O.C. p. 624).

2) En la visión del Aleph el narrador dice:

"...vi tu cara..." (O. C. p. 626).

Magnífica metalepsis en la que el narratario es introducido como un componente más de ese "inconcebible universo" (18).

3) En la posdata, que ya de por sí implica la presencia del narratario, aparece el adjetivo "nuestra" cuyo significado integra al yo que lo enuncia y al tú que lo escucha. La afirmación en la que aparece el adjetivo es respuesta a dos preguntas que se hace el narrador sobre el verdadero Aleph:

"Nuestra mente es porosa para el olvido..." (O. C. p. 628).

4) Finalmente, la dedicatoria a Estela Canto (19), colocada al final del cuento y con letra pequeña, casi escondida, es la última relación que establece el narrador con el narratario.

Como se ha visto el narrador homodiegético se denomina "Borges" y su edad sobrepasa los cuarenta años (20). "Borges" ofrece, según su objetivo, "un informe" sobre sus experiencias ante tres sucesos: su amor platónico, devoto y vano hacia Beatriz Viterbo, su conocimiento de la obra poética de Carlos Argentino Daneri y su visión totalizadora del universo a través del Aleph. El primer suceso lo aproxima a los otros dos y el tercero conforma la unidad del cuento.

El narrador reitera en su relato, el amor reverente que siente hacia el recuerdo de Beatriz, quien es evocada particularmente en dos ocasiones, en cada una con un diferente tipo de enumeración (21). La primera de la clase que denomina Spitzer caótica, y la segunda, anafórica. Ambas integran las partes en una visión totalizadora. La primera, el aspecto físico que dan los diferentes y numerosos retratos de Beatriz Viterbo y la segun$\mathrm{da}$, el sentimiento amoroso del narrador hacia su amada. Las dos resultan risibles: una, por las circunstancias triviales y por las poses ridículas de los retratos; la otra, la exaltación desmedida y ascendente del nombre de Beatriz, contrastando con la simpleza de la identificación:

“...soy yo, soy Borges" (O. C. p. 624).

El espíritu humorista se encuentra en todo el relato y si se toma en cuenta que en la posdata pone el protagonista en duda lo que vio y describió en páginas anteriores, se concluye que el narratario ha sido objeto de un juego paradójico y pleno de ironía, que contrasta con el afán de objetividad y con el espíritu reflexivo del narrador. En cuanto a lo primero, se explica con la acumulación de datos temporales, citas y notas al pie de página que dan verosimilitud a la diégesis; en cuanto al espíritu reflexivo, la relevancia que adquiere en este relato la función ideológica del narrador".

\section{E. "Emma Zunz".}

Se ubica el narrador de este cuento en un nivel extradiegético y mantiene respecto a la histo- 
ria una relación heterodiegética. Sin embargo, tanto el nivel como la relación, en dos breves momentos del cuento se deslizan hacia un tipo de narración intra-homodiegético, para continuar en seguida, presentando al narrador extra-heterodiegético.

Se aprecia como el narrador (22) conoce el mundo no sólo exterior de Emma sino también su interioridad, como lo establecen las dos citas siguientes:

"El catorce de enero de 1922, al volver de la fábrica de tejidos Tarbuch y Loewenthal halló en el fondo del zaguán una carta..." (O. C. p. 564).

Y luego,

“...comprendió que esa voluntad era inútil porque la muerte de su padre era lo único que había sucedido en el mundo, y seguiría sucediendo sin fin (Idem).

Elabora el narrador su relato ofreciendo detalles meticulosos del quehacer de Emma Zunz, desde ese día jueves hasta el sábado dieciséis de enero por la tarde y captando sus íntimos pensamientos; contrasta este rasgo del narrador con la actitud dudosa que manifiesta ante hechos objetivos como el siguiente: cuando Emma recibe la carta comunicándole la muerte de Emmanuel Zunz, dice el narrador:

"...firmaba la noticia, un tal Fein o Fain, de Río Grande, que no podía saber que se dirigía a la hija del muerto" ( $O$. C. p. 564).

Pero un poco más adelante, sobre la misma carta señala:

"...debajo del retrato de Milton Sills, donde la había dèjado la antenoche, estaba la carta de Fain" (O. C. p. 565).

En la narración las ideas y los sentimientos de Emma se dan por medio del narrador, es decir en un estilo indirecto; solamente en el desenlace de la historia aparecen las palabras que después del crimen pronunció Emma Zunz por teléfono:

"Ha ocurrido una cosa que e sincreíble... El señor Loewenthal me hizo venir con el pretexto de la huelga... Abusó de mí, lo maté..." (O. C. p. 568).

En su relato acude el narrador a los paréntesis para aclarar y reforzar (23) una acción, una idea o un elemento de la oración; véase el ejemplo que sigue: "...y después un vestíbulo (en el que había una vidriera con losanges idénticos a los de la casa en Lanús)" (O. C. p. 566).

En este ejemplo el contenido del paréntesis es fundamental para comprender el carácter de la protagonista, ya que envuelve al vestíbulo de la pensión en que Emma se dejará violar por un marinero, con un sentimiento de rechazo y de sumisión al acto que se propone, vinculado a recuerdos de su hogar $y$ de sus padres.

El narrador busca la atención de su narratario por el recurso apuntado y además, empleando interrogaciones y adverbios de duda; asimismo emplea el pronombre "nos" ( = yo + tú):

“...nos consta que esa tarde fue el puerto" (O. C. p. 565).

La cita transcrita muestra a un narrador, que si bien es verdad se ha manifestado en un nivel extradiegético, en un momento dado del relato se introduce en la historia como un fugaz narrador intradiegético, sin que haya explicación referida, es decir, se presenta una metalepsis narrativa. El pronombre "nos" incorpora no sólo el "yo" que narra, sino también al "tú" que escucha. El segundo se esfuma el desarrollo del cuento, mientras que el "yo" nuevamente asoma en una actitud de carácter dubitativo:

"Yo tengo para mí que pensó una vez..." (O. C. p. 565).

Es notorio tarnbién que el narrador pasa, abruptamente, de un tipo de relación a otro tipo. $Y$ luego, otra vez, pasa de ser observador de los hechos: Emma caminando por el Paseo de Julio, a un narrador heterodiegético que conoce la vida interior de su personaje y únicamente los puntos suspensivos separan ambas relaciones: la homodiegética de la heterodiegética; véase la cita siguiente:

“...más razonable es conjeturar que al principio erró, inadvertida, por la indiferente recova... Entró en dos o tres bares... De uno muy joven temió que le inspirara alguna ternura..." (O. C. p. 566).

El relato prosigue y el narrador heterodiegético se plantea una pregunta, cuya respuesta indecisa la da un "yo" y así, nuevamente, se incorpora el narrador homodiegético. La incorporación es fugaz y evidente con esta oración:

"Yo tengo par amí..." (O. C. p. 566). 
Esta cita al igual que las otras dos que la anteceden definen la incertidumbre del narrador ante los hechos objetivos vividos por el personaje y contrastan con el conocimiento definido de la interioridad de Emma Zunz que posee, como se da en la enumeración anafórica que reúne los recursos de la inferencia y de la adolescencia de Emma:

"Recordó veraneos... recordó (trató de recordar) a su madre... recordó la casita de Lanús... recordó los amarillos losanges... recordó el auto de prisión... recordó (pero eso jamás lo olvidaba) que su padre..." (O.C. p. 564).

\section{F. "EI Sur".}

El narrador de este cuento es extra-heterodiegético (24); empero en el desenlace del relato surge un deslizamiento del nivel extradiegético al intrediegético, estableciendo además, una relación con características inherentes a una relación homodiegética. Estos recursos acentúan el carácter fantástico del relato.

Se transcribirán a continuación las primeras oraciones del discurso:

"El hombre que desembarcó en Buenos Aires en 1871 se llamaba Johannes Dahlmann... en 1939, uno de sus nietos, Juan Dahlmann... se sentía hondamente argentino... en la discordia de sus dos linajes, Juan Dahlmann (tal vez a impulso de la sangre germánica) eligió el de ese antepasado romántico..." (O. C. p. 525).

En las dos oraciones que se han subrayado -la primera aseverativa, la segunda dubitativa- aparece un narrador que capta el pensamiento de Juan Dahlmann, pero que al emplear la oración dubitativa, indica que ese conocimiento interior no es pleno, sino que es semejante al de alguien que observara al personaje. Quiere ello decir que el narrador oscila, entre los rasgos de una relación heterodiegética y los de una homodiegética. Con esta característica el narrador desenvuelve su historia.

El narrador conoce el pasado y el presente de Juan Dahlmann, lo cual puede ser esquematizado de esta forma:

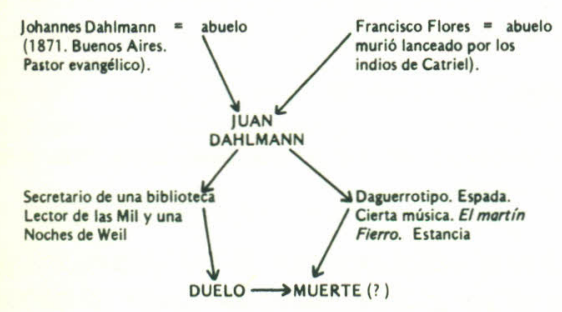

Su ascendencia alemana y no la argentina, según el narrador "tal vez" Ileva a Juan Dahlmann a elegir el linaje perteneciente a

"...ese antepasado romántico, o de muerte romántica". (Idem).

Sin embargo, como se señala en el esquema anterior ambos linajes influyen en Dahlmann, quien en el desenlace del cuento y de acuerdo con el narrador:

"Sintió que si él, entonces hubiera podido elegir o soñar su muerte, ésta es la muerte que hubierelegido o soñado" (O. C. p. 530).

También los sentimientos y los sueños de Dahlmann son percibidos por el narrador, quien los enuncia en un estilo indirecto, como se nota en las citas que siguen:

“...ávido de examinar ese hallazgo..." (O. C. p. 525).

"Alguna vez durmió y en sus sueños estaba el ímpetu del tren" (O. C. p. 527).

Excepcionalmente el narrador emplea el estilo directo en lo que Dahlmann piensa:

“Mañana despertaré en la estancia, pensaba..." (Idem).

"No hubieran permitido en el sanatorio que me pasaran estas cosas, pensó" (O. C. p. 529).

Esta perspectiva narrativa desde el personaje explica que el último párrafo del cuento se haya analizado como si fuese un pensamiento del personaje, cuando en realidad es el narrador, quien a modo de un testigo, describe la última acción del relato. Antes de la salida a la llanura el narrador conoce, con relativa certeza, el pasado y el presente de Juan Dahlmann; en cambio, el futuro a partir de esa salida es desconocido como lo clarifican el adverbio de duda y el tiempo futuro de esa oración:

"Dahlmann empuña con firmeza el cuchillo, que acaso no sabrá manejar, y sale a la llanura" (O. C. p. 530).

Concluir que en este relato aparece una doble muerte: la real una, en la sala de operaciones; soñada la otra, en el desenlace (25) significa apagar la fuerza, la presencia de lo fantástico. Si Borges afirma de este cuento 
“...que es posible leerlo como directa narración de hechos novelescos y también de otro modo" (O. C. p. 438),

es porque se está refiriendo a la característica de la lectura del texto fantástico, el cual no se agota en la primera lectura ya que en él existe, como lo designa Julio Cortázar:

“...la sospecha de otro orden más secreto y menos comunicable" (26).

Como se indicó lo fantástico de este relato se manifesta con gran eficacia en el efecto que produce la metalepsis narrativa siguiente: el narrador surge incorporado en la diégesis, es decir, se desliza del nivel extradiegético al intradiegético y establece al incorporarse una relación homodiegética con la historia que narra. En esta nueva posición contempla a Juan Dahlmann quien sale a pelear y ella explica que el narrador quien hasta el momento ha interiorizado en la conciencia del personaje, ignora ahora, lo que habrá de sucederle al sencillo bibliotecario en su duelo frente a un pendenciero compadrito, en la vasta y oscura llanura.

\section{G. "La intrusa".}

Extra-heteriodiegético es el narrador de "La intrusa" y muestra en la enunciación de su diégesis una serie de dudas que giran tanto alrededor de lo ocurrido, como a las fuentes de la misma. Así, inicialmente, afirma:

"Dicen (lo cual es improbable) que la historia fue referida por Eduardo... en el velorio de Cristián..." (O. C. p. 1025).

La oración que se ha subrayado es el complemento directo de una oración impersonal "Dicen" y entre ambas ha puesto, entre paréntesis, una aclaración que muestra que lo dicho es improbable. Esta explicación se fundamenta en el carácter silencioso de Eduardo frente al de Cristián, quien toma la iniciativa en los hechos narrados y de quien el narrador cita en forma directa algunas órdenes dadas a Eduardo, ante las cuales cuales calla y las acata.

Dos versiones sirven de base a la historia: la que Santiago Dabove (27) le contó, y la otra versión impersonal:

"Años después volvieron a contármela en Turdera, donde había acontecido" (Idem).
Naturalmente, según el narrador, entre ellas aparecen:

"...las pequeñas variaciones y divergencias que son del caso" (Idem).

Por el contexto del discurso no se puede deducir que cuando el narrador afirma:

"La escribo ahora porque en ella se cifra, si no me engaño, un breve y trágico cristal de la índole de los orilleros antiguos" (Idem).

se refiera a una versión particular de la historia, sino al tema de la misma.

También alude el narrador a una Biblia de tapas negras en cuyas páginas estaba escrita

"La azarosa crónica de los Nilsen..." (Idem).

El no leyó la crónica, sino que ésta fue leída por un párroco anterior al párroco de Turdera con quien habló el narrador.

De lo expuesto hasta aquí se deduce que el cuento "La intrusa" es una narración metadiegética, cuyos narradores (Santiago Dabove, el impersonal de "volvieron a contármela", Eduardo, el cura párroco) no se precisa quien enuncia la historia y en consecuencia, resulta imposible la caracterización del narrador intradiegético. Sí se puede afirmar que el narrador crea su relato con base en varias fuentes, que el texto no permite delimitarlas y que el narrador heterodiegético al apoyarse en las referencias testimoniales de carácter oral lo hace con el fin de fundamentar la verosimilitud del mundo narrado ante el narratario.

En cuanto a las dudas del narrador sobre la historia véanse los ejemplos siguientes:

1) El epígrafe dado por el narrador: "2 Reyes I, 26", no existe en las versiones en español de la Biblia que han sido consultadas; pero se destaca el versículo de "2 Samuel; I, 25 ", cuyo contenido sí tiene vinculación con el cuento $(28)$.

2) "Fue entonces, creo, que Eduardo lo [ = a Juan Iberra] injurió" (O. C. p. 1027).

3) "Acaso, alguna vez, se creyeron salvados". (Idem).

4) "El comercio del Pardo quedaba, creo, más al Sur..." (O. C. p. 1028).

En el señalamiento de las dudas, los paréntesis y el epígrafe el narrador alude al narratario 
también lo hace directamente en dos oportunidades:

"Esto y lo que ignoramos..." (O. C. p. 1026).

Así como en esta otra:

"Nadie sabrá los pormenores de esa sórdida unión, que ultrajaba la decencia del arrabal". (Idem).

El narrador describe a los hermanos por sus acciones. En la descripción de ambos insiste el narrador en lo unidos que fueron

"Malquistarse con uno era contar con dos enemigos" (Idem).

Así como en el sentimiento de esa unión:

"...el cariño entre los Nilsen era muy grande" (O. C. p. 1027).

De ahí que Juliana Burgos fuera la intrusa en esa relación, a pesar de que ambos la compartieron. Eliminada la intrusión, por el asesinato también compartido, Cristián le dice a Eduardo:

"Ya no hará más perjuicios" (O. C. p. 1028).

El narrador cierra su relato con una imagen de los hermanos abrazados y la presencia de un vínculo más de unión entre ellos: el asesinato de la intrusa.

\section{H. El informe de Brodie".}

Este cuento está formado por dos relatos bien delimitados. El narrador heterodiegético presenta el manuscrito de un informe al cual le falta la primera página y es escrito por el misionero escocés David Brodie.

El narrador extra-heterodiegético del primer relato muestra conocimientos limitados sobre el informe:

"...que yo sepa, no fue dado nunca a la imprenta" (O. C. p. 1073). poco:

Igualmente sobre el autor del informe conoce "Ignoro la fecha y el lugar de su muerte" (Idem).

El narrador declar aque traducirá con fidelidad el manuscrito. Esta declaración y el comenta- rio sobre la traducción de Lane de las Mil y Una Noches reflejan a un hombre de letras.

En cuanto al narrador intra-homodiegético se cuenta para su caracterización con dos perspectivas. La primera por los datos que de él suministra el narrador primero, a saber:

1) Misionero cirstiano, oriendo de Aberdeen, que predicó en Africa y Brasil.

2) Lector de las Mil y Una Noches, según esta cita:

"...a su lector le interesaron menos los prodigiosos cuentos de Sharazad que los hábitos de Islam". (Idem).

3) Latinista, ya que en el texto original había pasajes escritos en latín tomados de la Biblia unos y otros sobre la conducta sexual de los yahoos que

"...el buen presbiteriano confió pudorosamente al latín". (Idem).

La segunda perspectiva es la que de sí mismo da el narrador metadiegético en el desarrollo de su informe:

1) El interés que le anima para describir la vida y las costumbres de los yahoos es mayor que narrar sus experiencias:

"Mis aventuras en la selva no importan" (O. C. p. 1077).

2) El recato sexual se presenta cuando la reina de los yahoos se le ofrece:

"Mi hábito (my cloth) y mis hábitos me hicieron declinar ese honor..." (O. C. p. 1075).

3) Adopta las costumbres de los yahoos; por ello, cuando regresa a la civilización come como aquellos seres:

"Al principio me causaba algún asco verlo abrir la boca sin disimulo y echar adentro piezas de comida. Yo me tapaba con la mayo o desviaba los ojos; a los pocos días me acostumbré" (O.C. p. 1078).

4) Padece el horror de aquel pueblo:

"...su horror esencial, que nunca me deja del todo y que me visita en los sueños" (Idem). 
En cuanto al narratario se encuentra presente en ambos relatos. En el primero, por la evidencia que muestra el narrador por traducirlo y editarlo. En cuanto al segundo, porque Brodie atrae la atención del narratario, sostiene la comunicación con él. Al inicio del informe, en el que falta la primera página, dice:

"...de la región que infestan los hombres monos (Apemen) tienen su morada los M/ch... para que mis lectores no olviden..." (O. C. p. 1073).

Más adelante se refiere a un acontecimiento que narró en la primera página, la cual se perdió del original, y lo empieza a resumir así:

"He referido ya cómo arribé a la tierra de los Yahoos. EI lector recordará que..." (O. C. p. 1077).

Al concluir su informe concretiza al narratario y lo involucra en la acción que habrá de tomarse en el futuro:

"Tenemos el deber de salvarlos. Espero que el Gobierno de Su Majestad no desoiga lo que se atreve a sugerir este informe" (O. C. p. 1078).

\section{I. "El Otro"}

El narrador de este relato (29) ocupa un nivel extradiegético y con la diégesis establece una relación homodiegética; el narrador se va caracterizando con el desdoblamiento de su persona: el joven y el viejo, quien narra. El desdoblamiento es también a nivel de espacio.

El anciano, quien está sentado en un banco, frente al río Charles, siente la presencia de otro personaje. Luego de escucharlo silbar, recuerdos de la juventud del anciano llegan a su memoria y se dirige a la persona que está próxima a él, concluye que es un joven, a quien le dice, luego de hacerle dos interrogaciones y como conclusión de las respuestas respectivas, lo siguiente:

"En tal caso... usted se llama Jorge Luis Borges. Yo también soy Jorge Luis Borges. Estamos en 1969, en la ciudad de Cambridge" (Borges, El libro de arena, p. 11).

"Borges", el joven, le contradice al tiempo y el lugar, en su contradicción está presente el desdoblamiento espacial y se intensifica el de la persona:

"Yo estoy aquí en Ginebra, en su banco, a unos pocos pasos del Ródano. Lo raro es que nos parecemos, pero usted es mucho mayor, con la cabeza gris" (Idem).
El diálogo entre ambos, el viejo y el joven, continúa; este constituye el único acontecimiento de la diégesis.

El narrador subraya el carácter de obra literaria que le da a la enunciación de sus recuerdos de aquella mañana de febrero de 1969. Apréciese lo dicho en estas dos citas:

“...pienso que si lo escribo, los otros lo leerán como un cuento..." (dem), p. 9).

"Soñó, ahora lo entiendo, la imposible fecha en el dólar" (Idem, p. 21). (30).

El narrador autodiegético se caracteriza básicamente como literato, pero se refiere a otras actividades suyas, como es la labor docente:

“.. mi clase de la tarde anterior había logrado, creo, interesar a los alumnos" (Idem, p. 9).

Recuerda las lecturas de su juventud, que son las mismas del otro: El Quijote, la Germania de Táctico, Las Mil y una Noches de Lane, el Sartor Resartus de Thomas Carlyle, las obras de Whitmann, Víctor Hugo. La experiencia que viven es matizada con una referencia literaria: la novela de Dostoievski El doble.

Un espíritu reflexivo y tranquilo muestra el narrador autodiegético cuando, por ejemplo, le anuncia al joven que perderá la vista con el paso de los años:

"No te preocupes. La ceguera gradual no es una cosa trágica. Es como un lento atardecer de verano" (dem, p. 21).

La presencia del narratario es muy importante para el narrador, ya que él al escribir la experiencia, sentirá lo narrado no como algo real, sino como un cuento:

“...los otros lo leerán como un cuento; con los años lo será tal vez par amí" (Idem, p. 11).

De "atroz" es calificada por el narrador la experiencia que el encuentro de él con el "otro".

El tono dubitativo que envuelve a la diégesis es evidente, cuando el narrador coloca en la duda la interpretación de los hechos:

"Creo haber descubierto la clave" (Idem, p. 21).

Además, el apego a la verosimilitud de los hechos hace que el narrador al recordar el momen- 
to en que lanzó una moneda a las aguas del río afirme con nostalgia:

"El arco del escudo de plata perdiéndose en el río de plata hubiera conferido a mi historia una imagen vivida, pero la suerte no lo quiso" (Idem. p. 20).

En resumen, se concluye que la disociación temporal del narrador crea un proceso dialéctico que permite que en la narración se incorporen dos temporalidades (1918 y 1969) del narrador (1918) con respecto de la temporalidad más reciente (1969) a la enunciación.

\section{CONCLUSIONES}

De acuerdo con lo expuesto y con la aplicación de los conceptos a nivel y de relación pertenecientes a la narratología de Gérard Genette se presenta la siguiente clasificación de los cuentos respecto al nivel narrativo:

1. Relatos metadiegéticos cuya estructura responde, con evidencia, al principio del relato dentro del relato. Aquí están: "Hombre de la esquina rosada" y "El informe de Brodie".

2. Relatos cuyo nivel es extradiegético: "Funes el memorioso" y "El otro".

3. Relatos cuyo nivel corresponde al extradiegético, en apariencia, pero que la presencia de las posdatas y la alusión a "otros narradores" dispone la narración en un nivel intradiegético; es el caso de los cuentos: "Tlön, Uqbar, Orbis Tertius", "Las ruinas circulares", "El Aleph" y "La intrusa".

4. Relatos en que el recurso de la metalepsis permite deslizar el relato del nivel extradiegético al nivel intradiegético, con un predominio estructural del primer nivel, como se comprueba en los cuentos "Emma Zunz" y "El Sur".

En lo que concierne a la relación del narrador con la historia los cuentos estudiados se ubican en los grupos siguientes:
1. Relatos que incorporan, por su naturaleza metadiegética, dos narradores bien definidos. En el caso de "Hombre de la esquina rosada" y "El informe de Brodie", cuyos narradores de primer grado son heterodiegéticos y los de segundo grado, homodiegéticos.

2. Relatos en los cuales el narrador es homodiegético, que aparece en "Funes el memorioso" y autodiegético en "EI Aleph" y "El otro".

3. Relatos en que el narrador es heterodiegético: "Las ruinas circulares" y "La intrusa", aunque el narrador de este último cuento deja entrever la posibilidad de que uno de los personajes de su historia la haya narrado, tiempo atrás.

4. Relatos en que el narrador aparentemente, es heterodiegético, pero que se desliza hacia formas homodiegéticas: "Tlön, Uqbar, Orbis Tertius", "Emma Zunz" y "El Sur".

Finalmente, se demuestra que el mundo narrado de estos relatos se dispone en las formas de una narración metadiegética y se destaca que la relación del narrador con la diégesis, es predominantemente, de carácter homodiegético.

La estructura de tales relatos refleja una concepción del universo como un libro, los hombres son las palabras y la existencia de un autor único. Precisamente, estas ideas junto con otros rasgos importantes de la obra de Borges han influido en la literatura francesa como lo destaca Michel Beaujour, cuando enfoca el por qué ciertas obras adquirieron, a principios de la década de los sesenta, reputación y ejercieron cierta influencia en los novelistas del "noveau roman". He aquí la afirmación de Beaujour:

\footnotetext{
"Pero es sobre todo Jorge Luis Borges quien se ofrece como maestro de los laberintos, de las bibliotecas circulantes y del libro capaz de engendrar un mundo; él marca también el límite de lo que los franceses pueden intentar sin caer en el plagio" (31).
} 


\section{NOTAS Y CITAS BIBLIOGRAFICAS}

(1) Gérard Genette. "Discours du récit, essai de méthode". Figures III. Editions du Seuil, 1972), p. 232. De ahora en adelante, cuando sea citada esta obra se colocará junto a la cita sólo el número de la página correspondiente.

(2) La cita de Jorge Luis Borges corresponde al ensayo "Magias parciales del Quijote". Cfr. Obras completas (Buenos Aires, Emecé, 1974), p. p. 667-669. De aquí en adelante, cuando se dé una referencia de las Obras completas de Borges se colocará junto a la cita la abreviatura 0 . C. y el número de página correspondiente.

(3) Véase la siguiente frase que aparece en el relato: "Tlön, Uqbar, Orbis Tertius": "Todos los hombres que repiten una línea de Shakespeare, son William Shakespeare". (O. C. p. 438). Asimismo en su ensayo "Sobre Chesterton", Borges afirma lo siguiente: "Amplificando un pensamiento de Attar... Jalal-uddin Rumi compuso unos versos... donde se dice que en los cielos, en el mar y en los sueños hay Uno sólo..." ( O. C. p 695).

(4) La información de los siete primeros relatos de la lista apuntada fue tomada de la siguiente obra: Jaime Alazraki. La prosa narrativa de Jorge Luis Borges. (Madrid, Gredos, 1972), p. p. 408-409. De estos siete relatos, con excepción de "El Sur" les introdujo Borges modificaciones que son transcritas y comparadas por Alazraki, en la obra citada, con los textos definitivos. Cfr. Alazraki. Idem, p. p. 383-406.

(5) En la traducción al inglés del libro El informe de Brodie se da sobre el cuento "La intrusa", Ia siguiente nota bibliográfica: "...was first published in an edition of fifty-two copies illustrated by Emilio Centurión and privately printed by the Buenos Aires bibliophile Gustavo Fillol Day in April 1966. It also appeared, the same month, in the sixth impression of the third edition of El Aleph (Emecé, 1966), where it continued to appear until the twelfth impression, issued November 1970; here it was removed from the text but is erroneously listed in the table of contents". Jorge Luis Borges Doctor Brodie's Report. (Norman Thomas di Giovanni in collaboration with the autor, U.S.A., Penguin Books, 1976), p. 105.

(6) Cfr. Jorge Luis Borges. O. C. p. p. 713-716. Así como la última parte del ensayo "El espejo de los enigmas", O. C. p. p. 721-722.

(7) Al concluir el ensayo "Del culto de los libros", Borges hace una cita indirecta de León Bloy, la cual dice: “...según Bloy, somos versículos o palabras o letras de un libro mágico, y ese libro incesante es la única cosa que hay en el mundo: es, mejor dicho, el mundo" (O. C. p. 716). Véase también la cita directa que sobre este mismo asunto, hace Borges de
León Bloy, en la página 722 de sus Obras completas.

(8) Los hechos ocurridos "...esa noche" poseen su reverso: la versión que ofrece el narrador primero ("Borges") en su "Historia de Rosendo Juárez" le fue contada por su protagonista-Rosendo- en "...un bar en la calle Bolívar y Venezuela... hacia mil novecientos treinta y tantos"; Rosendo ha sido un lector de la historia que Borges publicó ("Hombre de la esquina rosada"): "Usted, señor, ha puesto el sucedido [la noche que mataron al Corralero] en una novela, que yo no estoy capacitado para apreciar, pero quiero que sepala verdad sobre esos infundios". (O. C. p. 1034).

(9) Cfr. Tzvetan Todorov. Introducción a la literatura fantástica. (Trad. Silvia Delpy. 2a. edic., Buenos Aires, Tiempo Contemporáneo, 1974), p. 105.

(10) El narrador de "Tlön, Uqbar, Orbis Tertius" crea un mundo ficticio empleando recursos propios del ensayo, razón por la cual Jean de Milleret ha dicho que en "Tlön, Uqbar, Orbis Tertius" "hay un equilibrio casi perfecto entre los dos géneros [cuento y ensayo]". Entrevistas con Jorge Luis Borges (Trad. G. Rodríguez. Caracas, Monte Avila, 1970), p. 98. Sin embargo "Tlön..." es un excelente relato, y no un ensayo, cuya esencia es, según Theodor Adorno, la de "...limitarse a ordenar de un modo nuevo cosas que ya en algún momento fueron vivas. $Y$ como se limita a ordenarlas de un modo nuevo, en vez de dar forma a algo nuevo a partir del informe, se encuentra vinculado a ellas, tiene que decir siempre la 'verdad' acerca de ellas, y 'hallar expresión de su esencia' ". En Theodor Adorno. "El ensayo como forma". Del mismo autor Notas de literatura (Trad. M. Sacristán. Barcelona, Ariel, 1962), p. 11.

(11) Del cuento "Las ruinas circulares" se ha dado la siguiente apreciación: "...un mago sueña a un hombre, crea un hijo desde la niebla de su imaginación, para darse cuenta, en el momento de su propia extinción, 'con alivio'... que otro estaba soñándoIo". Ariel Dorfman. "Borges y la violencia". Del mismo autor: Imaginación y violencia en América. (Santiago, Edit. Universitaria, 1970), p. 41. Tal afirmación es considerada como no valedera, porque afirmar que el mago alcanza su "extinción" es una idea que no se desprende del texto ya que él no puede morir, él es un simulacro de hombre que desaparecerá cuando el dios fuego despierte y al hacerlo dejará de soñarlo y entonces se esfumará la presencia del mago; de éste, la de su hijo y así sucesivamente.

(12) El relato "Las ruinas circulares"' se considera mítico, porque en él se genera una realidad sobrenatural, cuya existencia no provoca interferencia en la vigilia o en el sueño del lector; en consecuencia, el texto no lo obliga, según lo explica Todorov, a “...consi- 
derar el mundo de los personajes como un mundo de personas reales, y a vacilar entre una explicación natural y una explicación sobrenatural de los acontecimientos evocados". En Tzvetan Todorov. Op. cit., p. p. 43-44.

(13) Este carácter ambiguo, de acuerdo con Todorov, surge por la siguiente razón: "En tanto narrador, su discurso no debe ser sometido a la prueba de verdad; pero en tanto personaje, puede mentir". En T. Todorov. Idem, p. 101.

(14) Se considera fático el discurso por cuanto el narrador incorpora en el acontecer que cuenta, al narratario; no lo separa, en cuyo caso sería el discurso conativo; al contrario, el narrador lo incorpora en la diégesis. Para los conceptos de función fática y de función conativa véase a Roman Jakobson "Lingüística y poética". Del mismo autor Ensayos de lingüistica general (Barcelona, Seix Barral, 1975), p. p. 355-356.

(15) Cfr. Harry Belevan. Teoría de lo fantástico. Apuntes para una dinámica de la literatura fantástica. (Barcelona, Anegrama, 1970), p. 122.

(16) A propósito de este título se recoge la siguiente información biográfica: "1919. En Espagne. La famille Borgès réside principalment à Barcelona et à Palma de Majorque. Borgès travaille a deux ouvrages que ne seront jamais édités:... et Los naipes del tahur qui dénote, au dire même Borgès, I' influence de l'écrivain espagnol Pío Baroja". E. Rodríguez Monegal. Borgès par lui-même (París, Seius, 1970), p. 182.

(17) Cfr. Borges O. C., nota 1, p. 418 y p. 695.

(18) Sobre este punto, un crítico borgiano señala: “...no se da el antecedente, pero puede ser Beatriz Viterbo". Cfr. D. Foster "Para una caracterización de la escritura en los relatos de Borges", Revista Iberoamericana. (V. 43, Nos. 100, 101, 1977), p. 348. Sin embargo, dado el carácter integrador de la visión que da el Aleph, resulta más explicable la presencia de una metalepsis narrativa, en la que el narratario es incorporado en la diégesis.

(19) Sobre Estela Canto (1920-) Jean de Milleret, en una nota, dice de ella lo siguiente: "Escritora argentina que sacrificó su talento a la política. Borges le dedicó "El Aleph". En Jean de Milleret. Op. cit., p. 174.

(20) En este relato y como ya se indicó en la nota No. 16 de este trabajo, se reflejan datos biográficos de su creador, como es este otro ejemplo: la obra del narrador, "Borges", es presentada para el "Premio Nacional de Literatura" e "increíblemente... no logró un solo voto"; Jorge Luis Borges, con El jardín de senderos que se bifurcan -1941- "...se presentó al premio nacional de literatura y no lo obtuvo; resultaron premiadas obras de escaso mérito literario. La indignación fue general; a tal punto, que la revista Sur publicó un número especial de desagravio a Borges..." Alicia Jurado. Genio y figura de Jorge Luis Borges. (2a. edic., Buenos Aires, Eudeba, 1966), p. 42.

(21) Cfr. Leo Spitzer "La enumeración caótica en la poesía moderna”. Del mismo autor Lingürística e historia literaria. (Trad. de Raimundo Lida. Madrid, Gredos, 1955), p. 307.

(22) En el marco de la concepción borgiana de la obra dentro de la obra y la presencia de un autor único, resulta interesante la observación que en el Epílogo de su libro El Aleph presenta: "Fuera de 'Emma Zunz' (cuyo argumento espléndido, tan superior a su ejecución temerosa, me fue dado por Cecilia Ingenieros)..." (O. C. p. 629).

(23) Sobre los diversos usos del paréntesis en los textos de Jorge Luis Borges, comenta Ana María Barrenechea, entre otros asuntos, el suguiente: "Todo paréntesis, al cortar la línea del relato para intercalar un momentario, es un llamado de atención al lector como si se subrayase el texto para destacarlo". Ana M. Barrenechea. La expresión de la irrealidad en la obra de Borges. (Buenos Aires, Paidós, 1967), p. p. 198 y ss.

(24) De este cuento reconoce Borges ante James E. Irby que: "El Sur est un conte assez autobiographique, tout au moins dans ses premières pages". J. E. Irby. "Entretiens avec James E. Irby". L.Herne (Paris, 1964), p. 397.

(25) Sobre la "muerte soñada" comenta un crítico de la obra de Borges: "...es altamente significativo observar que la muerte soñada constituye una liberación $y$, por extensión, una redención en el momento final del cuento". Allen W. Phillips. "El Sur de Borges". Revista hispánica moderna. (V. 29, No. 2, 1963), p. 144.

(26) Cfr. Julio Cortázar "Algunos aspectos del cuento". Casa de las Américas (No. s. 15-16, 1962), p. 4.

(27) Santiago Dabove (1889-1960). Narrador amigo de Borges. Este le prologó su libro de cuento $L a$ muerte y su traje. Ahí manifiesta Borges que Dabove "...vivía en Morón, pueblo de sus padres, abuelos y trasabuelos". Más adelante agrega: "...le interesaba la crónica épica de las orillas, las historias de guapos". Jorge Luis Borges. Prólogos. (Buenos Aires, Torres Agüero, 1975), p. 50 y p. 51, respectivamente.

(28) El por qué este error no ha sido enmendado, podría ser explicado como la incertidumbre que, a modo de acto lúdico, planteara el narrador ante el narratario. Sin embargo, en la edición norteamericana de $E I$ informe de Brodie referida en la nota No. 5 de este estudio se lee el epígrafe con los datos concordantes con la diégesis del relato: 2 Samuel: I, 26.

(29) Se reitera que este cuento pertenece a El libro de arena (1975), que en consecuencia, no forma parte 
de las Obras completas, cuya edición de 1974 se ha citado aquí.

(30) Sobre la génesis de esta historia Borges afirma lo siguiente: "Se me ocurrió ese cuento en un viaje a los Estados Unidos, pensé que sería curioso tener una conversación con él que fui y ver si habíamos cambiado mucho en la manera de pensar, en los gustos literarios... creo que alguien me dijo que los billetes de dólar no llevaban año y que por lo tanto el intercambio de pruebas quedaba invalidado, pero ahora usted confirma mi sospecha de que si tienen fecha". Marcos R. Bernatán. Borges y su obra. (Barcelona, Dopesa, 1978), p. p. 118-119.

(31) Michel Beajuour "Francia, la novela de la novela.'. Varios. La nueva novela europea. (Trad. M. García-Viño. Madrid, Guadarrama, 1968, p. 96.

\section{BIBLIOGRAFIA}

\section{Teórico-metodológica}

\section{a) Básica}

Genette, Gérard. "Discours du récit, essai de méthode". Figures III. Paris, Editions du Seuil, 1972 , p. p. $65-276$.

."Fronteras del relato". Barthes et al. Análisis estructural del relato. Trad. Beatriz, Berriots. Buenos Aires, Tiempo Contemporáneo, 1972. p. p. 193-208.

\section{b) Complementaria}

Adorno, Theodor. "El ensayo como forma". Notas de literatura. Barcelona, Ariel, 1962. p. p. 11-56.

Barrenechea, Ana María. "Ensayo de una tipología de la literatura fantástica". Revista Iberoamericana. 38 (80), jul.-set. 1972. p. p. 391-403.

Beaujour, Michel. "Francia: la novela de la novela". En: Kurz et. al. La nueva novela europea. Trad. García-Viño. Madrid, Guadarrama, 1968, p. p. 81-98.

Belevan, Harry. Teoría de lo fantástico. Apuntes para una dinámica de la literatura de expresión fantástica. Barcelona, Anagrama, 1970. 126 p. p.

Booth, Wayne C. La retórica de la ficción. Trad. Santiago Gubern Garriaga-Nogués. Barcelona, Antoni Bosch, 1978.

Cortázar, Julio. "Algunos aspectos del cuento". Casa de las Américas. Nos. 15-16.1962, pp. 314-316.
Coste, Didier. "Trois conceptions du lecteur et leur contribution a une théorie du texte littéraire". Poétique. No. 43. 1980, p. p. 354-371.

Gennete, Gérard. "La littérature selon Borges". L' Herne, 1964. p. p. 323-327.

Hahn, Oscar. El cuento fantástico hispanoamericano en el siglo XIX. México, Premiá, 1978. 183 p. p.

Hernadi, Paul. Teoría de los géneros literarios. Trad. Carlos Agustín. Barcelona, Bosch, 1978. 175 p. p.

Jakobson, Roman. "Lingüística y poética". Del mismo autor: Ensayos de lingüística. Trad. Joseph M. Pujol y Jem Cabanes. Barcelona, Seis Barral, 1975. p. p. 347-395.

Margery, Enrique. "Alcances en torno a la problemática del narrador". Revista de Filología y Lingüística. Universidad de Costa Rica, No. 1. Mayo, 1975. p. p. 55-82.

Martínez Bonati, Félix. La estructura de la obra literaria. 2a. ed., Barcelona, Seix Barral, 1972. 244 p. p.

Spitzer, Leo. "La enumeración caótica en la poesía moderna". Del mismo autor: Lingüística $e$ historia literaria. Madrid, Gredos, 1955. p. p. 295-355.

Todorov, Tzvetan. Introducción a la literatura fantástica. Trad. Silvia-Delpy. Buenos Aires, Tiempo Contemporáneo, 1972. 212 p. p. 
Vax, Louis. Arte y literatura fantástica. 2 ed., Buenos Aires, EUDEBA, 1971. 128 p. p.

\section{Del Corpus}

Borges, Jorge Luis. Obras Completas. Buenos Aires, Emecé, 1974. Emecé, 1975.

El libro de arena. Buenos Aires,

3. Otras obras del autor

Borges, Jorge Luis et. al. Antología de la literatura fantástica. 4a. ed. Prólogo y posdata de Adolfo Bioy Casares. Buenos Aires, Sudamericana, 1971.

. Manual de zoología fantástica. México, Fondo de Cultura, 1972. (Col. Breviarios).

Leopoldo Lugones. Buenos Aires, Pleamar, 1965. 114 p. p.

. Prólogo de prólogos. Buenos Aires, Torres Agüero, 1975. 176 p. p.

. "Me orias de Borges". Ancora: La Nación 18-25 de mayo de 1975. 15-22-29 de junio de 1975. 6 de julio de 1975.

Doctor Brodie's Report. (Norman Thomas di Giovanni in collaboration with the autor) U.S.A., Penguin Books, 1976.

Emecé, 1977.

. Historia de la noche. Buenos Aires,

- Borges, oral. Buenos Aires, Emecé Belgrano, 1979.

. Siete noches. México, Fondo de Cultura Económica, 1980. (Col. Tierra Firme).

4. Sobre el corpus y sobre su autor

\section{a) Libros}

Alazraki, Jaime. La prosa narrativa de Jorge Luis Borges: definición de temas y análisis de estilo. 2 ed., Madrid, Gredos, 1974. 435 p.p.
. Versiones. Inversiones. Reversiones. El espejo como modelo estructural del relato en los cuentos de Borges. Madrid, Gredos, 1977. (Campo abierto).

Barnatan, Marcos R. Borges y su obra. Barcelona, Dopesa, 1978. 124 p.p.

Barranechea, Ana María. La expresión de la irrealidad en la obra de Borges. Buenos Aires, Paidós, 1967. 270 p. p.

Bastos, María Luisa. Borges ante la crítica argentina 1923-1960. Buenos Aires, Hispamérica, 1974. 356 p. p.

Bosco, María Angélica. Borges y los otros. Buenos Aires, Libros del Mirasol, 1967. 170 p. p.

Jurado, Alicia. Genio y figura de Jorge Luis Borges. $2^{\circ}$ ed. Buenos Aires, EUDEBA, 1966. 191 p. p.

Rodríguez Monegal, Emir. Borgès par lui-même. Paris, Seuil, 1970. 190 p.p.

Sosnowski, Saúl. Borges y la cábala. La búsqueda del verbo. Buenos Aires, Hispamérica, 1978. 118 p.p.

\section{b) Artículos de revistas.}

Borinski, A. "Re-escribir y escribir: Arenas, Menard, Borges Cervantes, Fray Servando". En: Revista Iberoamericana. 43 (100-101). 1977. p. p. $549-560$.

Dorfman, Ariel. "Borges y la violencia americana". En: del mismo autor Imaginación y violencia en América. Santiago, Editorial Universitaria, 1970. p. p. 38-64.

Echavarría, Ferrari, A. "Tlön, Uqbar, Orbis Tertius": creación de un lenguaje y crítica del lenguaje". Revista Iberoamericana. 43 (100-101). 1977, p. p. 399-413.

Foster, David W. "Para una caracterización de la escritura en los relatos de Borges". Revista Iberoamericana. 43 (100-101). 1977. p.p. 337-355. 
Fuentes, Carlos. "La constitución borgiana". En: del mismo autor, La nueva novela hispanoamericana. México, Mortiz, 1969, p. p. 23-26.

Jitrik, Noé. "Estructura y significación en Ficciones de Jorge Luis Borgès". En: del mismo autor, El Fuego de la especie. Buenos Aires, Siglo XXI, 1971. p. p. 129-150.

Mourey, Jean Pierre. "Le texte et sa fiction chez Jorge Luis Borgès. Mirages et miroirs". Poétique. No. 45 , 1981, p. p. 67-78.

Phillips, Allen W. "El Sur de Borges". Revista hispánica moderna. 29 (2). 1963. p. p. 140-147.

Rest, Jaime. "Borges y el espacio literario". Hispamérica. No. s. 11-12. 1975. p.p. 3-21.

Rodríguez, Alma Silvia. "Una interpretación y comentario sobre la técnica narrativa del Aleph de Jorge Luis Borges". Humanitas. No. 12, 1971. p. p. $217-224$

Rodríguez Moengal, Emir. "Borges el lector como escritor" Imagen Nos. 58-59. Agosto de 1972. Cuarto cuerpo. p. p. 10-13.
Santander, Carlos. "Estructura narrativa en hombre de la esquima rosada". Revista Chilena de Literatura. No. 11. 1970. p. p. 23-30.

Sosnowski, Saúl. "El verbo cabalístico en la obra de Borges". Hispamérica. No. 9. 1975. p. p. 35-54.

\section{c) Entrevistas}

Barone, Orlando (Com.). Diálogos. Jorge Luis Borges-Ernesto Sábato. Buenos Aires, Emecé, 1976. 198 p. p.

Charbonnier, Georges. El escritor y su obra. México, Siglo XXI, 1967, 92 p. p.

Guibert, Rita. "Entrevista con Borges". En: Jaime Alazraki. Jorge Luis Borges. Madrid, Taurus, 1976. p. p. 318-355.

Irby, James. "Entretiens avec James E. Irby". L' Herne. 1964. p. p. 388-403.

Milleret, Jean de. Entrevistas con Jorge Luis Borges. Traducción G. Rodríguez. Caracas, Monte Avila, 1970.186 p. p.

Ocampo, Victoria. Diálogo con Borges. Buenos Aires, Sur, 1969, 85 p. p. 